\title{
Reservations to Participate in Biospecimen Research among Pacific Islanders
}

\author{
Patchareeya Kwan ${ }^{1}$, Greta Briand ${ }^{2}$, Cevadne Lee ${ }^{1}$, Jonathan Lepule ${ }^{3}$, Karen Llave ${ }^{4}$, Ka’ala \\ Pang $^{2}$, Melanie Sabado ${ }^{1}$, Lola Santos ${ }^{5}$, Sora Tanjasiri ${ }^{3}$, \\ Vanessa Tui'one ${ }^{6}$, Dorothy Schmidt-Vaivao ${ }^{7}$, and Paula Palmer ${ }^{1}$ \\ ${ }^{1}$ Claremont Graduate University, School of Community and Global Health \\ ${ }^{2}$ Pacific Islander Health Partnership \\ ${ }^{3}$ California State University Fullerton, Department of Health Science \\ ${ }^{4}$ California State University Northridge, Department of Health Science \\ ${ }^{5}$ Guam Communications Network, Inc. \\ ${ }^{6}$ Tongan Community Service Center/Special Services for Groups \\ ${ }^{7}$ Samoan National Nurses Association
}

\begin{abstract}
Background and Significance: Despite high rates of chronic diseases like cancer, diabetes and cardiovascular disease, Pacific Islanders (PIs) are underrepresented in clinical and genetic studies designed to identify the physiological causes of poor health outcomes. There are limited genetic data and biospecimen samples from PIs under study. This paper described why PIs have reservations about donating their biospecimen samples for research. Methods: Data were drawn from a pilot study designed to assess the knowledge, attitudes and beliefs surrounding biospecimen research among PIs in southern California. Utilizing a community-based participatory research approach, community and academic partners collected quantitative and qualitative data from a total of 60 PI adults with a mean age of 61 years (SD 13 years). Results: "Fear", "God or Spirituality" and "Lack of Information or Knowledge" were the most cited reasons for not participating in biospecimen research. Respondents younger than age 65 years expressed more concerns about donating their biospecimen samples than those older than age 65 years $(p<0.012)$. No significant gender differences were found $(p=0.84)$. Conclusion: Our results emphasize the need to conduct relevant and appropriate biospecimen education among minority communities in order to address misconceptions and build support to increase PI and other minority participation in biospecimen-related studies.
\end{abstract}

(c) 2015 Californian Journal of Health Promotion. All rights reserved.

Keywords: Pacific Islanders, community-based participatory research, biospecimen, participation, willingness

\section{Introduction}

Research over the past two decades have established the difficulties of recruiting ethnic minorities to medical and behavioral research studies (Hilton et al., 2010; Hoel et al., 2009; Hussain-Gambles, Atkin, \& Leese, 2004; Shavers-Hornadaya, Lynch, LF, \& Torner, 1997; Wang, Fridinger, Sheedy, \& Khoury, 2001). Researchers are beginning to understand that such populations often have structural, cultural and language barriers that hinder their participation (Ford et al., 2008; Giuliano et al., 2000). Furthermore, reasons for non- participation are rooted in cultural and religious beliefs (Kwan et al., 2014). Participation rates for Pacific Islanders (PIs) (i.e. people of Polynesian, Melanesian and Micronesian descent) are much lower than their African American, Hispanic and Asian counterparts. Even as a combined group, Asian Americans and Pacific Islanders account for less than 10\% of the respondents in most research studies (Chlebowski et al., 2005; Ford, et al., 2008; Giuliano, et al., 2000; Murthy, Krumholz, \& Gross, 2004). This paper reports on pilot data regarding the reasons that deter PI participation in biospecimen-related research. 
Epidemiological data have shown that PIs suffer disproportionately high rates of health disparities compared with most other racial and ethnic groups (Dachs, Currie, \& McKenzie, 2008; $\mathrm{OMH}, 2012)$. Cancer, heart disease, stroke and diabetes are among the major causes of morbidity and mortality among PIs. Despite these large disparities, research aimed at addressing the underlying causes of disease and illness have had limited success at recruiting and retaining participants. An extensive review examining the barriers to recruiting underrepresented populations to cancer clinical trials found that low participation rates for ethnic minorities are related to lack of awareness about the nature of the studies, lack of culturally relevant materials, and mistrust in researchers (Ford, et al., 2008). Some participants are reluctant to participate because of self-perceived harm of clinical trials and loss of control as it relates to treatment. One study cited found that lack of trust in researchers and the institutions involved were also major barriers for minorities, due to incidents of abuse and unethical conduct in the past (Santos, 2008).

Between 2010 and 2012, a pilot research project built upon the successes of the National Cancer Institute Community Network Program Center called WINCART: Weaving an Islander Network for Cancer Awareness, Research and Training (Tanjasiri \& Tran, 2008; Tanjasiri et al., 2007) explored the knowledge, attitudes and beliefs that PIs have towards biospecimenrelated research. The study collected both quantitative and qualitative data from adult PIs, 21 years of age or older, and asked what they thought about biospecimen (explained as urine, blood, hair, nail and skin samples) collection, research, and banking. Details about the specific conceptual model, methods, instruments and results have been reported in a previous paper that found general support for biospecimen research among PIs (Kwan et al., 2014). The majority of the PIs interviewed did support biospecimen research, and were willing to donate their biospecimen sample if asked. In order to better understand why such support has not translated into actual donations and inform future biospecimen collection-related studies, this paper reports on the findings that relate to PIs' reluctance to participate in studies that involve biospecimen samples. Based on previous efforts completed among minority populations and general discussions with community leaders, the authors believed that PIs are reluctant to participate in biospecimenrelated research because of a lack of awareness about the studies and its potential benefits to individuals and community (Fong, Braun \& Chang, 2003; Ford, et al., 2008). It should be noted that the results presented in this paper pertain only to those respondents who responded with hesitation about donating biospecimens for research.

\section{Methods}

\section{Study Design}

Utilizing a community-based participatory research (CBPR) approach, PI community leaders from five community-based agencies in Los Angeles, Orange and San Diego counties worked with the academic researchers to conduct this mixed methods study. The community-university team developed the conceptual model, screening and recruitment materials and qualitative and quantitative study instruments.

\section{Sample}

Eligible participants were those who selfidentified as being PI, over the age of 21 years and living in the southern California area. Participants were recruited through word-ofmouth, at PI festivals and events and through flyers posted and distributed in community partner organizations. Since this was a pilot study, the sample was a convenience sample of PIs who received services from the community organizations (i.e. health education classes, health insurance information, health screenings and referrals, etc.) or those who knew the health educators in various capacities. In addition, study team members actively recruited cancer survivors because of their unique experiences with biospecimen collection during their cancer diagnosis and/or treatment activities. 


\section{Measures}

Approved by the Institutional Review Board at Claremont Graduate University, the study instruments consisted of a 46-item paper and pencil questionnaire and a semi-structured oneon-one interview. The paper and pencil questionnaire included demographic, acculturation, health status and cancer history items. Whenever applicable, standardized scales such as the health locus of control scale (Wallston, 1978) and the acculturation scale (AHIMSA) (Unger et al., 2002) were adapted and used in the questionnaire. The interview questions assessed respondents' satisfaction with providing biospecimen samples, willingness to donate, and perceived threats and risks of participating in biospecimen-related studies. For example, we asked "What would stop you, if anything, from personally volunteering to take part in tissue sample research?", "What might be some reasons why a person might not want to participate in genetic research?” and "In your opinion, how might tissue sample research harm your community?”

\section{Data Collection}

Data was collected by trained PI health educators at their offices, and all took place in one day. Health educators scheduled one-on-one meetings with each respondent after they were recruited to the study and agreed to participate. Each meeting ranged from approximately 1 to 1.5 hours (i.e. 20-30 minutes to complete the paper and pencil questionnaire which was followed immediately by a 40-60 minute oneon-one interview). Respondents were offered breaks in between the questionnaire and interview portions, although most did not need it. Due to the nature of the data collection method, respondents were not scheduled together and all data collection was done individually.

\section{Data Analysis}

Quantitative data analysis was conducted in STATA version 10.0. Basic univariate data analyses were conducted to find the mean age and gender, ethnic and educational level distributions. Frequencies are presented in Table 1.
ATLAS.ti was used to code the transcripts into various themes such as reservations, satisfaction, willingness and trust. Each time a respondent provided an answer, it was coded under a particular theme and sub-theme, if appropriate (e.g. "reservation: fear" or "reservation: lack of knowledge"). It was not uncommon for a certain theme to be expressed by a respondent more than once and thus certain themes and subthemes appeared more frequently in an interview transcript than others (i.e. a respondent may have expressed that he/she had "reservations about providing samples because of fear" multiple times throughout the interview). The percentage of coded responses for a particular concern about biospecimen donation is defined as the number of responses coded for the reason divided by the total number of coded responses for the entire sample (i.e. 1601 coded responses).

\section{Results}

As shown in Table 1, a total of 60 PIs were interviewed for this study, half of whom were over the age of 65 years. Twenty-one out of the 60 respondents were male. The largest PI ethnic groups in the sample were Native Hawaiians, Samoans and Chamorros. A majority of the respondents had completed high school and post-high school education. Forty one (68.3\%) respondents shared that they had some reservations or reluctance about providing their biospecimens for research. A total $53.3 \%$ of the respondents aged 65 years or older had reservations about donating biospecimen samples, compared to $83.3 \%$ of respondents younger than age 65 who expressed their reservation. A similar proportion of males and females expressed some form of reservation. A majority of the Chamorro and Tongan respondents reported having reservations about participating in biospecimen studies (83.3\% and $77.8 \%$, respectively). Education level was not related to whether or not a respondent had reservations. 
Kwan, P., Briand, G., Lee, C., Lepule, J., Llave, K., Pang, K., Sabado, M., Santos, L., Tanjasiri, S., Tui'one, V., Vaivao, D.S., Palmer, P. / Californian Journal of Health Promotion 2015, Volume 13, Issue 3, 27-33.

Table 1

Respondent Characteristics ( $\mathrm{N}=60)$

\begin{tabular}{|c|c|c|c|c|c|}
\hline & & $\mathrm{n}$ & $\begin{array}{l}\text { Respondents } \\
\text { expressing } \\
\text { reservations } \\
\mathrm{n}(\%) \\
\end{array}$ & $\chi^{2}$ & $\mathrm{p}$ \\
\hline \multicolumn{6}{|l|}{ Age } \\
\hline & $\begin{array}{l}\text { 65+ years } \\
\text { (range = 65- } \\
85 \text { ) }\end{array}$ & 30 & $16(53.3 \%)$ & 6.2 & 0.012 \\
\hline & $\begin{array}{l}\leq 65 \text { years } \\
\text { (range= } 32- \\
64)\end{array}$ & 30 & $25(83.3 \%)$ & & \\
\hline \multicolumn{6}{|c|}{ Gender } \\
\hline & Male & 21 & $14(66.7 \%)$ & 2.4 & 0.84 \\
\hline & Female & 39 & $27(69.2 \%)$ & & \\
\hline \multicolumn{6}{|c|}{ Ethnicity } \\
\hline & $\begin{array}{l}\text { Native } \\
\text { Hawaiian }\end{array}$ & 21 & $12(57.1 \%)$ & 5.5 & 0.49 \\
\hline & Samoan & 13 & $9(69.2 \%)$ & & \\
\hline & Chamorro & 12 & $10(83.3 \%)$ & & \\
\hline & Tongan & 9 & 7 (77.8\%) & & \\
\hline & Marshallese & 3 & $2(66.7 \%)$ & & \\
\hline & Paluan & 1 & $1(100.0 \%)$ & & \\
\hline & N.Z. Maori & 1 & $0(0.0 \%)$ & & \\
\hline \multicolumn{6}{|c|}{ Education } \\
\hline & $\begin{array}{l}\text { Less than } \\
\text { H.S. }\end{array}$ & 3 & $2(66.70 \%)$ & 2.6 & 1.0 \\
\hline & H.S./GED & 22 & $15(68.2 \%)$ & & \\
\hline & Post H.S. & 28 & 19 (67.9\%) & & \\
\hline & $\begin{array}{l}\text { College } \\
\text { graduate }\end{array}$ & 7 & $5(71.4 \%)$ & & \\
\hline
\end{tabular}

Table 2 shows the specific reasons why PIs reported having reservations about biospecimen donation. Fear of pain and finding out that something might be wrong with their health was the most common reason why PIs had reservations (41.5\%). This particular response comprised $1.3 \%$ of all 1,601 coded responses in the study. God or spirituality and lack of knowledge about biospecimen research were the next two most common reasons. Both responses comprised $1.2 \%$ of coded responses, with more respondents expressing their reservations due to lack of knowledge (39.0\%) rather than to God or spirituality (26.8\%). Less frequently cited responses included: beliefs that biospecimen, and thus genetic research, are involved with cloning or scrutiny of genes (12.2\%), and that biospecimen studies involve personal information, which may come back to harm them later (9.8\%).

A majority of the female respondents expressed "fear" (76.5\%) as their main reason for having reservations about donating their biospecimen sample followed by "lack of knowledge" (56.3\%) and "God or spirituality" (72.7\%). Male respondents shared similar reasons except that "fear" was cited less often than "lack of knowledge" among males (23.5\% and 43.8\%, respectively). When analyzed by age, respondents over the age of 65 years indicated that "fear" was their main reason for having reservations (35.3\%) while those younger than 65 years cited "lack of knowledge" as their main reason $(81.3 \%)$.

Table 2.

Reasons for Reservations by Respondent Characteristics

\begin{tabular}{|c|c|c|c|c|c|c|}
\hline Reasons & $\begin{array}{c}\% \text { out of } \\
1,601 \text { coded } \\
\text { responses } \\
\end{array}$ & $\begin{array}{c}\text { n (\%) out of } \\
41 \\
\text { people } \\
\end{array}$ & & & & \\
\hline & & & Males & Females & $65+$ years & $<65$ years \\
\hline $\begin{array}{l}\text { General, unexplainable } \\
\text { reservation }\end{array}$ & $0.4 \%$ & $6(14.6 \%)$ & $1(16.7 \%)$ & $5(83.3 \%)$ & $2(33.3 \%)$ & $4(66.7 \%)$ \\
\hline $\begin{array}{l}\text { Lack of information or } \\
\text { knowledge }\end{array}$ & $1.2 \%$ & $16(39.0 \%)$ & 7 (43.8\%) & $9(56.3 \%)$ & $3(18.7 \%)$ & $13(81.3 \%)$ \\
\hline Fear & $1.3 \%$ & 17 (41.5\%) & $4(23.5 \%)$ & $13(76.5 \%)$ & $6(35.3 \%)$ & $11(64.7 \%)$ \\
\hline God, spirituality & $1.2 \%$ & $11(26.8 \%)$ & $3(27 / 3 \%)$ & $8(72.7 \%)$ & $3(27.3 \%)$ & $8(72.7 \%)$ \\
\hline Cloning, scrutiny of genes & $0.5 \%$ & $5(12.2 \%)$ & $2(40.0 \%)$ & $3(60.0 \%)$ & $1(20.0 \%)$ & $4(80.0 \%)$ \\
\hline Insurance or lack of & $0.2 \%$ & $2(4.9 \%)$ & $0(0.0 \%)$ & $2(100 \%)$ & $0(0.0 \%)$ & $2(100 \%)$ \\
\hline $\begin{array}{l}\text { Lazy, don't know it is } \\
\text { important }\end{array}$ & $0.2 \%$ & $3(7.3 \%)$ & $1(33.3 \%)$ & $2(66.7 \%)$ & $1(33.3 \%)$ & $2(66.7 \%)$ \\
\hline Want money to participate & $0.1 \%$ & $2(4.9 \%)$ & $1(50.0 \%)$ & $1(50.0 \%)$ & $0(0.0 \%)$ & $2(100.0 \%)$ \\
\hline $\begin{array}{l}\text { Not comfortable with } \\
\text { providers/researchers }\end{array}$ & $0.1 \%$ & $2(4.9 \%)$ & $0(0.0 \%)$ & $2(100.0 \%)$ & $1(50.0 \%)$ & $1(50.0 \%)$ \\
\hline $\begin{array}{l}\text { Private information, might } \\
\text { harm them later with } \\
\text { employment }\end{array}$ & $0.4 \%$ & $4(9.8 \%)$ & $1(25.0 \%)$ & $3(75.0 \%)$ & $1(25.0 \%)$ & $3(75.0 \%)$ \\
\hline
\end{tabular}


Kwan, P., Briand, G., Lee, C., Lepule, J., Llave, K., Pang, K., Sabado, M., Santos, L., Tanjasiri, S., Tui'one, V., Vaivao, D.S., Palmer, P. / Californian Journal of Health Promotion 2015, Volume 13, Issue 3, 27-33.

Table 3 provides a sample of selected quotes from the interviews conducted. For confidentiality purposes, only the gender and ethnicity of the respondents are provided.

Table 3.

Selected Quotes by Reasons

Reasons (Number of responses)

Lack of information or knowledge (16)

“...lack of understanding, knowledge. That's the only think I can think of that would prevent them from doing it.” Female, Native Hawaiian

“Um I don't know maybe their scared and not really sure what the research is for I think ugh if doctors educate people properly they would probably have more people willing to participate.” - Male, Chamorro

\section{Fear (17)}

“...a lot of our Polynesian society doesn’t want to know. They actually feel that as long as they don't know, it is not happening. Cause there's a lot of people still living in the back, you know. You know, back in the olden days when you don't talk about it, you don't see it, then it is not happening. I think, they have to be educated. But educated in the basics, so they can understand what is being done and what is being said them." - Female, Native Hawaiian

\section{God, spirituality (11)}

“...the whole idea with genetic research is um, something that I need to think about more, cause I consider myself a spiritual person and I believe God is the only one that can, should create life and um, so it, it might bother me more than normal" - Female, Native Hawaiian

"Yup, yup. And I understand they need to do some of these things better, but sometimes they get a little crazy and you know, to me, overstep the bounds between man versus God, our creator” - Female, Native Hawaiian

“...I'd rather leave that up to God”-Female, Marshallese

\section{Cloning, scrutiny of genes (5)}

"Um, more Frankenstein kind of stuff. You know, what the heck are they going to do with me. Are they going to slice my genes and goat and see if we are more alike than not. Genetic research kinda scares me. Spiritually, I don't. I back away from it.” - Male, Native Hawaiian

"yeah I just don't want people using my genetics to make monkeys," - Female, Tongan

\section{Discussion}

To our knowledge, this pilot study is the first of its kind to report on the reservations that PIs living in the continental U.S. have towards biospecimen research. We found that PIs have authentic reservations that hinder their participation such as fear of pain and not wanting to find out about potential health problems. These findings are consistent with previous research studies conducted among African American and Hispanic communities (Corbie-Smith, Thomas, Williams, \& MoodyAyers, 1999; Giuliano, et al., 2000; ShaversHornadaya, et al., 1997). Through our interviews and informal discussions with PIs, we learned that some PIs would rather not know about their health problems. These individuals think that if they do not know about their health problems then the problems do not exist (i.e. it is better to not know). Some respondents expressed that even if they learned about their health problems, they would not change their views because of the belief that disease and death are beyond their control.

As mentioned earlier, the major finding obtained from the overall pilot study was general support for biospecimen research (Kwan, et al., 2014). Many PIs indicated that they support research that will benefit others in their community and are willing to provide biospecimen samples for that specific purpose if asked to do so. However, a small but important proportion of respondents expressed reluctance to participate personally in research. "Reservations" as a combined theme made up less than $6 \%$ of the total coded responses. This means that among all the responses that were coded (i.e. 1,601 total coded responses), reservations only comprised $6 \%$ of those responses. It is imperative that researchers better understand respondents' fears and misgivings if we are to increase PI and other minority involvement in research in the future.

\section{Limitations}

Several limitations existed in this study that should be noted. First, because this was a pilot study the sample size was small $(\mathrm{N}=60)$, and thus respondent fears may not reflect the beliefs of the larger PI population. Further, we did not 
employ random sampling and thus our findings might not reflect the knowledge, attitudes and beliefs of PIs living in other parts of the U.S. or around the world. For instance, a majority of our respondents were U.S. born, and thus their relatively higher levels of western acculturation may be unique to PIs in the region covered by our study. Second, close to two-thirds of our sample was female and over half were cancer survivors. The experiences of cancer survivors are different from that of the general population because they have been more exposed to clinical practices like blood drawing and biopsies. Cancer survivors also have more exposure to health care providers and medical and research staff during their diagnosis and treatment.

\section{Implications}

Although drawn from a small sample of PIs in southern California, we hope the findings from this study provide researchers with valuable information that helps in the planning of and recruitment to research studies among PIs and other minorities. Since the participation of minorities in biospecimen research is essential to reductions in health disparities, it is important that all factors, whether they encourage or hinder participation, be reviewed, carefully considered and properly addressed. If we can address the fear and reluctance that potential respondents have about our studies - whether through improve recruitment methods, more outreach and education about our studies or through a more user-friendly informed consent form - participation, enrollment and retention of minorities may be improved.

\section{Acknowledgement}

This study was funded by the National Cancer Institute's Center to Reduce Cancer Health Disparities (NCI CRCHD), grant number 5U54CA153458. The content is solely the responsibility of the authors and does not necessarily represent the official views of the NCI CRCHD.

\section{References}

Chlebowski, R., Chen, Z., Anderson, G., Rohan, T., Aragaki, A., Lane, D., et al. (2005). Ethnicity and breast cancer: Factors influencing differences in incidence and outcome. Journal of the National Cancer Institute, 97(6), 439-448.

Corbie-Smith, G., Thomas, S. B., Williams, M. V., \& Moody-Ayers, S. (1999). Attitudes and beliefs of African Americans toward participation in medical research. Journal of General Internal Medicine, 14(9), 537-546.

Dachs, G., Currie, M., \& McKenzie, F. (2008). Cancer disparities in indigenious Polynesian populations: Maori, Native Hawaiians, and Pacific people. The Lancet Oncology, 9(5), 473-484.

Fong, M., Braun, K., \& Chang, M. (2004). Native Hawaiian preferences for informed consent and disclosure of results from research using stored biological specimens. Pacific Health Dialog, 11(2), 154-159.

Ford, J. G., Howerton, M. W., Lai, G. Y., Gary, T. L., Bolen, S., Gibbons, M. C., et al. (2008). Barriers to recruiting underrepresented populations to cancer clinical trials: A systematic review. Cancer, 112(2), 228-242.

Giuliano, A. R., Mokuau, N., Hughes, C., Tortolero-Luna, G., Risendal, B., Ho, R. C. S., et al. (2000). Participation of minorities in cancer research: The influence of structural, cultural, and linguistic factors. Annals of Epidemiology, 10(8 Suppl), S22-34.

Hilton, C., Fitzgerald, R., Jackson, K., Maxim, R., Bosworth, C., Shattuck, P., et al. (2010). Brief report: Under-representation of African Americans in autism genetic research: A rationale for inclusion of subjects representing diverse family structures. Journal of Autism and Developmental Disorders, 40(5), 633-639.

Hoel, A. W., Kayssi, A., Brahmanandam, S., Belkin, M., Conte, M. S., \& Nguyen, L. L. (2009). Underrepresentation of women and ethnic minorities in vascular surgery randomized controlled trials. Journal of Vascular Surgery, 50(2), 349-354. 
Kwan, P., Briand, G., Lee, C., Lepule, J., Llave, K., Pang, K., Sabado, M., Santos, L., Tanjasiri, S., Tui'one, V., Vaivao, D.S., Palmer, P. / Californian Journal of Health Promotion 2015, Volume 13, Issue 3, 27-33.

Hussain-Gambles, M., Atkin, K., \& Leese, B. (2004). Why ethnic minority groups are under-represented in clinical trials: A review of the literature. Health \& Social Care in the Community, 12(5), 382388.

Kwan, P., Briand, G., Lee, C., Lepule, J., Pang, J., Sabado, M., et al. (2014). Use of a community-based participatory research approach to assess knowledge, attitudes, and beliefs on biospecimen research among Pacific Islanders. Health Promotion Practice, 15(3), 422-430.

Murthy, V. H., Krumholz, H. M., \& Gross, C. P. (2004). Participation in cancer clinical trials race-, sex-, and age-based disparities. Journal of the American Medical Association, 291(22), 2720-2726.

OMH. (2012). Native Hawaiian and Pacific Islander Profile. Retrieved August 8, 2012, from http://minorityhealth.hhs.gov/templates/browse.aspx?lvl=2\&lvlID=71.

Santos, L. (2008). Genetic Research in Native Communities. Progress in Community Health Partnerships, 2(4), 321-327.

Shavers-Hornadaya, V., Lynch, C., LF, B., \& Torner, J. (1997). Why are African Americans under-represented in medical research studies? Impediments to participation. Ethnicity \& Health, 2(1-2), 31-45.

Tanjasiri, S., \& Tran, J. (2008). Community capacity for cancer control collaboration: Weaving an Islander Network for Cancer Awareness, Research and Training for Pacific Islanders in Southern California. Cancer Detection and Prevention, 32 Suppl 1, S37-40.

Tanjasiri, S., Tran, J., Palmer, P., Foo, M., Hanneman, M., Lee, C., et al. (2007). Developing a community-based collaboration to reduce cancer health disparities among Pacific Islanders in California. Developing Human Resources in the Pacific, 14(1), 114-122.

Unger, J., Gallahen, P., Shakib, S., Ritt-Olson, A., Palmer, P., \& Johnson, C. (2002). The AHIMSA Acculturation Scale: A new measure of acculturation for adolescents in a multicultural society. The Journal of Early Adolescents, 22, 225-251.

Wallston, K. e. a. (1978). Health Locus of Control. Health Education Monographs, 6, 160-170. Wang, S., Fridinger, F., Sheedy, K., \& Khoury, M. (2001). Public attitudes regarding the donation and storage of blood specimens for genetic research. Community Genetics, 4, 18-26.

\section{$\underline{\text { Author Information }}$}

Patchareeya Kwan, Assistant Professor, Department of Health Science, California State University Northridge at 18111 Nordhoff St, Northridge, CA. 91330, email patty.kwan@csun.edu and tele. (818)677-6992

* corresponding author 